\title{
Effect of Temperature-Force Factors and Concentrator Shape on Impact Fracture Mechanisms of 17Mn1Si Steel
}

\author{
S. V. Panin, ${ }^{1,2}$ P. O. Maruschak, ${ }^{3}$ I. V. Vlasov, ${ }^{1,2}$ D. D. Moiseenko, ${ }^{1}$ \\ F. Berto, ${ }^{4}$ and A. Vinogradov ${ }^{4}$ \\ ${ }^{1}$ Institute of Strength Physics and Materials Science, SB RAS, Tomsk, Russia \\ ${ }^{2}$ National Research Tomsk Polytechnic University, Tomsk, Russia \\ ${ }^{3}$ Ternopil Ivan Pul'uj National Technical University, Ternopil, Ukraine \\ ${ }^{4}$ Department of Mechanical and Industrial Engineering, Norwegian University of Science and Technology, Trondheim, Norway
}

Correspondence should be addressed to S. V. Panin; paninsergey71@gmail.com

Received 8 September 2016; Accepted 5 December 2016; Published 23 January 2017

Academic Editor: Yuri Ribakov

Copyright (C) 2017 S. V. Panin et al. This is an open access article distributed under the Creative Commons Attribution License, which permits unrestricted use, distribution, and reproduction in any medium, provided the original work is properly cited.

\begin{abstract}
The influence of the notch shape on the impact fracture of $17 \mathrm{Mn} 1 \mathrm{Si}$ steel is investigated at different temperatures with the focus placed on the low-temperature behavior. An approach towards fracture characterization has been suggested based on the description of elastic-plastic deformation of impact loaded specimens on the stage of crack initiation and growth at ambient and lower temperatures. The analysis of the impact loading diagrams and fracture energy values for the pipe steel $17 \mathrm{Mn} 1 \mathrm{Si}$ revealed the fracture mechanisms depending on the notch shape. It was found that the testing temperature reduction played a decisive role in plastic strain localization followed by dynamic fracture of the specimens with differently shaped notches. A classification of fracture macro- and microscopic mechanisms for differently notched specimens tested at different temperatures was proposed which enabled a self-consistent interpretation of impact test results.
\end{abstract}

\section{Introduction}

A common tendency in transportation pipeline development, particularly for main gas and oil pipelines, is a gradual increase in their service life and performance [1]. The problem is particularly acute since the pipelines often operate in unfavorable weather conditions, for example, at low temperatures. A challenging task in this respect is to extend the service life of pipe steel structures by improving their mechanical properties [2]. Specifically, the fracture toughness, the major characteristic of crack resistance, has to be increased $[3,4]$. Procedures and equipment for fracture toughness testing are well standardized, ensuring good reproducibility of results [5].

Pipe steel structures are highly sensitive to the technological process of their manufacturing. Variations in technological variables result in considerable scatter of properties along the pipelines, increasing the probability of sudden damage and failure [5, 6]. Main detrimental factors affecting the strength and crack resistance of pipe steel are attributed to tensile stresses and corrosion of the outer surface of pipes arising in underground conditions due to delamination or rupture of protective coating and localized corrosion of the inner surface [7].

Currently available approaches to characterizing the base metal ductility allow estimating the dynamic crack initiation conditions that are crucial for the prevention of gas and oil pipeline failure [3]. Developing robust methods for the fracture energy determination in pipe steel with account of the shape of stress concentrators, for example, the defect tip radius, is important. These data can be used to account for the influence of embrittlement factors on the impact deformation resistance of pipe steel.

Furthermore, analysis of the literature data [4-8] shows that modern low-carbon steel structures produced by thermomechanical processing of the initial sheet have different sensitivity to the concentrator shape and temperature/force loading parameters. It is therefore important to understand 
TABLE 1: Impact test conditions for 17Mn1Si steel specimens.

\begin{tabular}{lll}
$\begin{array}{l}\text { Notch } \\
\text { shape }\end{array}$ & $\begin{array}{c}\text { Notch tip Concentrator } \\
\text { radius, } R, \\
\mathrm{~mm} \\
\text { length, } \\
\mathrm{mm}\end{array}$ & $\begin{array}{c}\text { Testing } \\
\text { tempera- } \\
\text { ture, } \\
{ }^{\circ} \mathrm{C}\end{array}$ \\
I-notch & & \\
\hline
\end{tabular}

the fracture mechanisms operating at different stress stiffness values. The significance of this problem can further be underscored by a wide range of practical applications associated with the interpretation of elastic-plastic characteristics of fracture resistance of structural materials in the presence of service defects [7].

The present paper is aimed at obtaining a deeper insight into the influence of the notch shape on the impact fracture of $17 \mathrm{Mn} 1 \mathrm{Si}$ steel at different temperatures with a focus on the low-temperature fracture behavior.

\section{Experimental}

Specimens for investigation were cut by spark erosion from a pipe steel sheet of $30 \mathrm{~mm}$ thickness produced by the Machine Building Factory of Yurga (Russia). A batch of specimens, $10 \times 10 \times 55 \mathrm{~mm}[9,10]$, with $\mathrm{V}$-, U-, and I-shaped notches of equal depth $(2 \mathrm{~mm})$, was machined. $\mathrm{V}$ - and $\mathrm{U}$-notches were introduced by standard milling cutters; I-notches were made by electroerosion. Before low-temperature impact testing, the specimens were kept in a cooling chamber, Lauda rp870, for 10 minutes in the temperature range from $-60^{\circ} \mathrm{C}$ to $0^{\circ} \mathrm{C}$. They were then rapidly mounted into the grips of the impact pendulum Instron 450MPX for testing. The time interval between the specimen extraction from the cooling chamber and further testing did not exceed 5 seconds. At least three specimens of each type were tested at temperatures 20, $0,-20$, -40 , and $-60^{\circ} \mathrm{C}$ (Table 1). The impact diagram was recorded as shown in Figure 1. The data processing software divides the specimen fracture energy into two constituents: load-time $(P-t)$ and load-curvature $(P-s)[9,10]$. The deformation and fracture mechanisms were studied by fracture surface images using a scanning electron microscope, LEO EVO 50 (Zeiss, Germany).

\section{Investigation Results}

3.1. Fracture Macromechanisms. Typically, for structural steel, the test temperature dependence of impact toughness
(Figure 1(a)) exhibits several characteristics regions [11, 12]. In the lower shelf (from $T=-60^{\circ} \mathrm{C}$ to $T=-40^{\circ} \mathrm{C}$ ), the specimen exhibits a fracture without pronounced signs of plastic deformation. The increase of the test temperature up to about $-20^{\circ} \mathrm{C}$ results in combined brittle and ductile fracture mechanisms. The upper shelf (from $-0^{\circ} \mathrm{C}$ to $20^{\circ} \mathrm{C}$ ) corresponds to the region of ductile fracture characterized by intensive plastic deformation on both micro- and macroscale. It is commonly accepted $[12,13]$ that fracture in each region is mediated by specific microscopic mechanisms.

It should be noted that the obtained temperature dependence of the impact toughness for specimens with sharp Vand I-notches almost coincides within the entire studied temperature range. Only at $-20^{\circ} \mathrm{C}$ was the impact toughness of $\mathrm{V}$-notched specimens slightly higher than that of I-notched specimens. On the whole, the impact toughness of U-notched specimens is about 3 times higher in the entire test temperature range than that of V-notched specimens (Figure 1). It can be assumed approximately that the impact toughness value for specimens with all three types of notches linearly decreases with the decreasing test temperature.

The obtained dynamic loading curves of the specimens corroborate their sensitivity to changes in the macrofracture localization conditions which are associated with the notch shape (Figure 1). The loading curve shape is typical of ductile fracture within the entire studied temperature range from $20^{\circ} \mathrm{C}$ to $-60^{\circ} \mathrm{C}$ [14] for all specimens tested including those with sharper V-and I-notches. The shape of the impact diagrams of the V-and I-notched specimens is almost the same, which indicates that crack initiation and growth occur similarly. In what follows, we consider details of these processes.

3.1.1. V-Notch. The specimens of $17 \mathrm{Mn} 1 \mathrm{Si}$ steel fracture in a ductile manner at test temperatures from $20^{\circ} \mathrm{C}$ to $-20^{\circ} \mathrm{C}$, which is evidenced by gradually ascending and descending parts of the loading curve (Figures $1(\mathrm{~b})-1(\mathrm{~d})$, curve V). The microscale deformation mechanisms result in effective stress relaxation [15]. The crack initiation and growth take place in a "classical" manner, that is, consecutively, without interruption and abrupt bifurcation transitions. The material shows high ductility and crack resistance. At $-40^{\circ} \mathrm{C}$ and $-60^{\circ} \mathrm{C}$, the fracture diagrams narrow and peak. The shape of the descending curve part points to brittle crack propagation $[15,16]$. This is especially typical of the test temperature $T=-60^{\circ} \mathrm{C}$ at which the maximum load decreases down to $P_{\max }=7 \mathrm{kN}$, which is indicative of a partial loss of the bearing capacity of the material [17].

3.1.2. I-Notch. The shape of the loading diagram (Figures $1(\mathrm{~b})-1(\mathrm{f})$, curve I) is similar to that of the specimen with the V-shaped concentrator (Figures 1(b)-1(f)). Hence, with the sharpest concentrator (compared to the V-notch; notch tip radius is 0.25 and $0.1 \mathrm{~mm}$, resp.), the fracture behavior of the material does not appear to be more brittle, even in the case of such a sharp notch similar in shape to a fatigue crack. In our opinion, this is due to the fact that plastic deformation ahead the tip of the main crack gives rise to partial stress relaxation during crack propagation in the studied steel. 


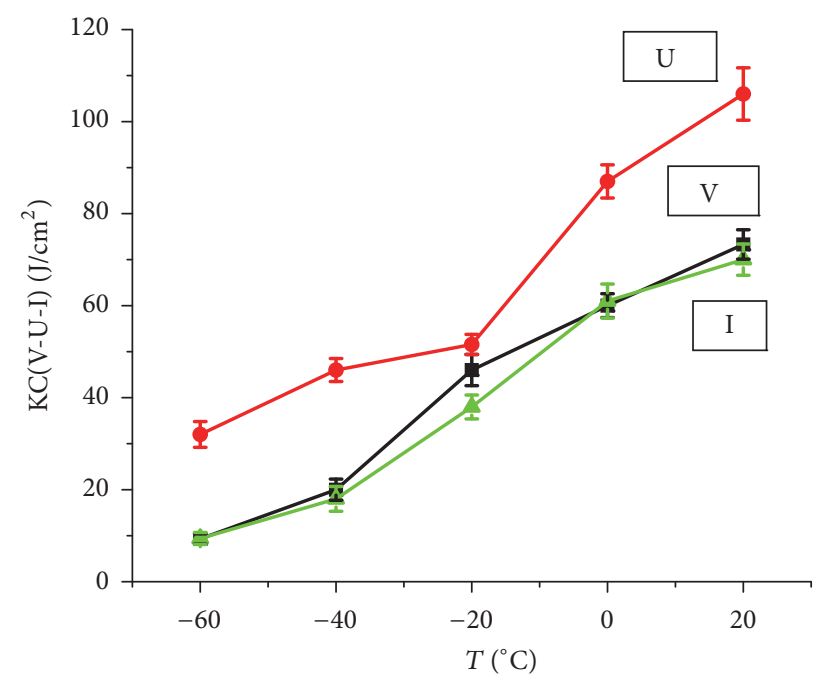

(a)

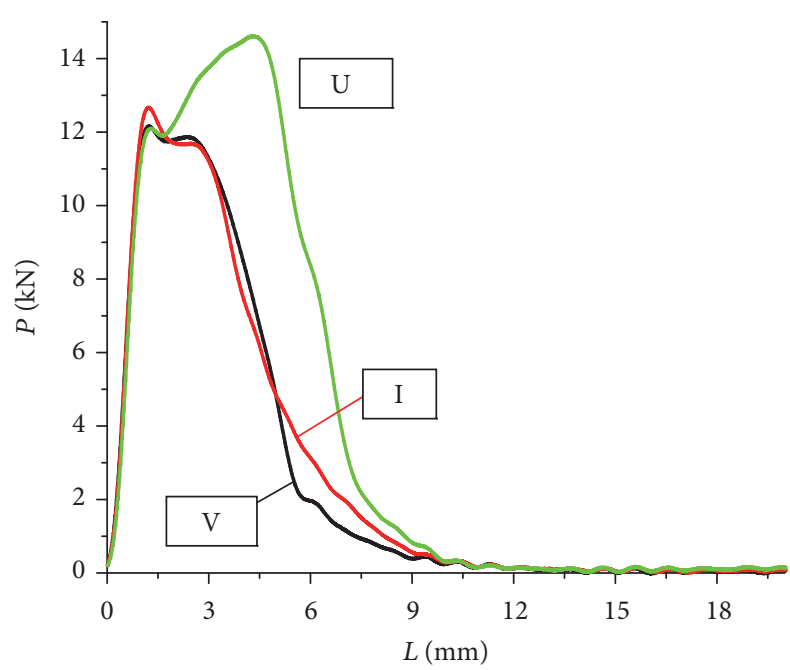

(c)

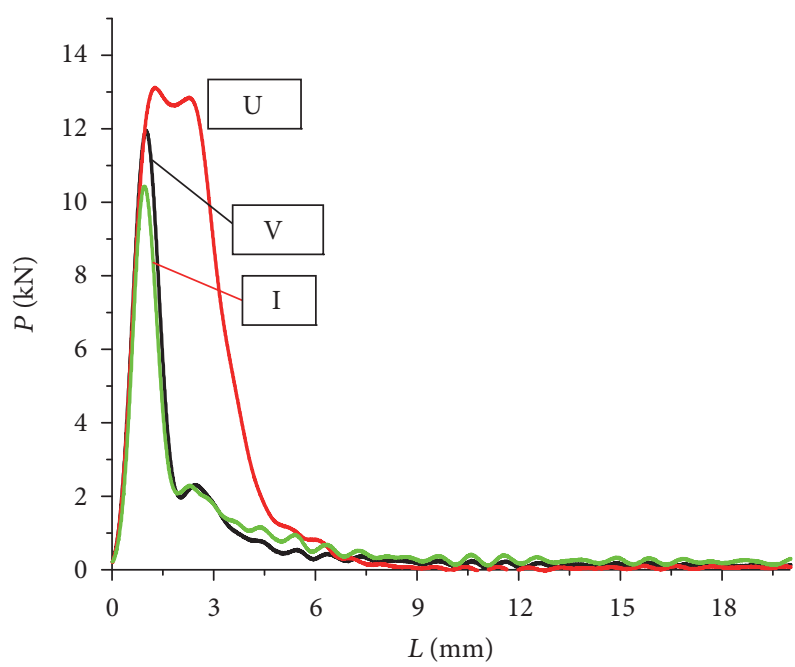

(e)

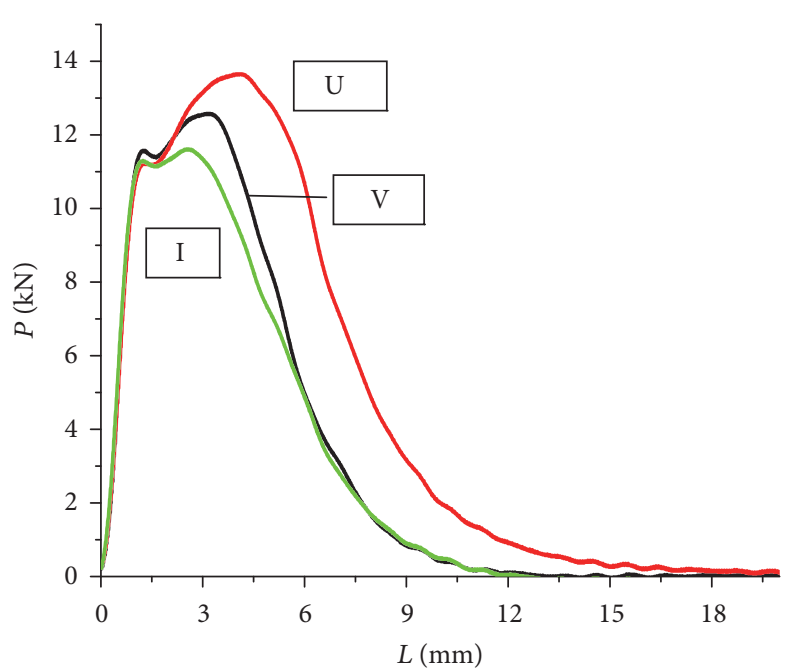

(b)

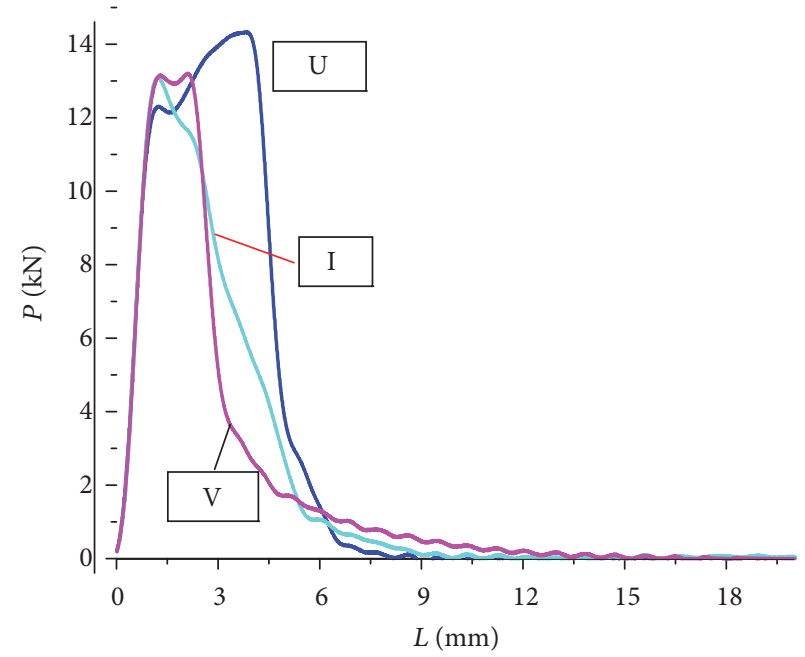

(d)

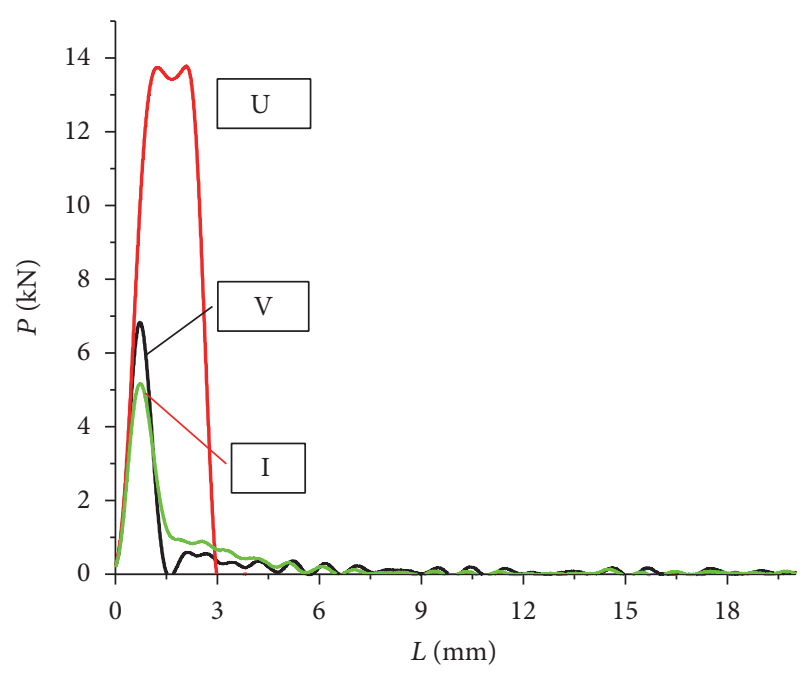

(f)

FIGURE 1: Temperature dependence of impact toughness (a); impact diagrams in the load/displacement coordinates at test temperatures: 20 (b), 0 (c), -20 (d), -40 (e), and $-60^{\circ} \mathrm{C}$ (f) for V-, U-, and I-notched specimens. 
TABLE 2: Maximum load values on impact diagrams.

\begin{tabular}{lccc}
\hline$T,{ }^{\circ} \mathrm{C}$ & V-notch & $\begin{array}{c}P_{\max }, \mathrm{kN} \\
\mathrm{U} \text {-notch }\end{array}$ & I-notch \\
\hline-60 & $6.8 \pm 0.2$ & $13.8 \pm 1.7$ & $5.2 \pm 0.1$ \\
-40 & $12 \pm 1.03$ & $13.1 \pm 1$ & $10.4 \pm 0.8$ \\
-20 & $13.2 \pm 1.01$ & $14.3 \pm 0.6$ & $13.1 \pm 1.3$ \\
0 & $12.2 \pm 1.02$ & $14.6 \pm 1.4$ & $12.7 \pm 1.2$ \\
20 & $12.6 \pm 2.3$ & $13.7 \pm 1.3$ & $11.6 \pm 1.5$ \\
\hline
\end{tabular}

The influence of the test temperature reduction for the Inotched specimens is similar to the influence described above for the $\mathrm{V}$-notched specimens. At $T=-60^{\circ} \mathrm{C}$, the maximum load value decreases even more abruptly down to $P_{\max }=$ $5 \mathrm{kN}$. This is testimony to a more pronounced embrittlement effect of the stress concentrator, which corresponds well to the minimum notch tip radius.

The yield plateau in the impact diagrams of I-notched specimens is only slightly seen. This is indicative of local hardening processes on early deformation stages, which are accompanied by a decrease in the resistance of steel to strain localization in bending (which is quite undesirable for pipelines).

3.1.3. U-Notch. The impact fracture of notched 17Mn1Si steel specimens with the maximum notch tip radius is accompanied by considerable plastic deformation. The observed macroscopic deformation behavior of the material bears witness to the activation of relaxation processes, which leads to an increase in the height and width of the impact diagram in the entire studied temperature range.

As one can see, the maximum load value decreases at room temperature (Figure 1(b)) with the growing stress concentration at the notch tip (in transition from the $\mathrm{U}$ - to the I-notch). The height of the yield point increases in this case and its peak in the I-notched specimen corresponds to the maximum load $P_{\max }$. Thus, an increase in the material volume involved in deformation resistance, like for the U-notch due to its larger radius, increases resistance to macrocrack initiation and growth. However, this occurs at lower values of load $P$ on the stage of elastic deformation as compared to the case of the I-shaped notch.

3.2. Integral Estimation of Impact Diagrams. From the viewpoint of experimental data application, one of the most important issues in postcritical deformation models is the determination of the point of transition to the postcritical stage of specimen deformation, that is, the stage of crack growth. Tables 2 and 3 show the force and energy parameters of impact toughness for $17 \mathrm{Mn} 1 \mathrm{Si}$ steel. Similar to the previous papers of some of the authors $[7,15]$, we may consider the maximum load in impact testing $P_{\max }$ as the macroscale characteristic that reflects the material strength.

These data are very important for understanding the effect of stress stiffness on the crack resistance of $17 \mathrm{Mn} 1 \mathrm{Si}$ steel because $P_{\max }$ corresponds to the point of transition from macrocrack initiation to propagation. The sharper the concentrator, the lower the value of the parameter $P_{\max }$ at which the crack grows, which is indicative of a stiffer stress state at the crack tip [15].

Additionally, as is known, the total fracture energy of Charpy specimens $\left(A_{t}\right)$ consists of two main parts: crack initiation energy $\left(A_{i}\right)$ and crack propagation energy $\left(A_{p}\right)$ (Table 3). Their analysis will be performed below.

\section{Discussion}

4.1. Energy and Deformation Parameters of Fracture. Hashemi [11] suggested that in the presence of an in-service defect the most important characteristic reflecting the material capability to the propagation of such defects was the crack propagation energy. Thus, he proposed the following fracture parameter:

$$
\mathrm{CF}=\frac{A_{t}}{\left(A_{t}-A_{i}\right)}
$$

Results of CF estimation, calculated from (1) for specimens with differently shaped notches within the studied test temperature range, are shown in Figure 2. The results demonstrate that $17 \mathrm{Mn} 1 \mathrm{Si}$ steel has significant ductility in the case of a sharp crack-like notch. In view of Hashemi's physical interpretation [11], the minimum CF value indicates that the least energy is needed for pipeline fracture arrest in the presence of a sharp crack-like notch.

It should be noted that the use of the CF parameter is pertinent in the presence of a large sharp defect in the pipe, or for pipes under long-term operation conditions, when

$$
\mathrm{CF}=\frac{A_{t}}{A_{p}} \approx 1 .
$$

Considering the steel in the as-supplied state, the present results show that the material has sufficient ductility. However, the CF parameter of steel decreases during operation.

Earlier, we studied Charpy specimens with in-service fatigue cracks [16]. This agrees with the assumptions of Sih and Tzou [17] and corroborates their physical correctness for ferrite-pearlite steel.

The impact toughness values of $17 \mathrm{Mn} 1 \mathrm{Si}$ steel determined by taking into account the total fracture energy of Charpy specimens are given in Table 4.

In the way of discussion, the authors would like to highlight a few features in the data shown in Tables 3 and 4. Firstly, the energy for crack initiation at $T=-40^{\circ} \mathrm{C}$ has dropped significantly while the energy for crack propagation increased. In fact, these experimental data deviate from the general trend of fracture energy variation as opposed to the pattern of the diagrams shown in Figure 1(a). Secondly, the same is true for the $\mathrm{V}$-shaped notch specimen fractured under impact bending at $T=0^{\circ} \mathrm{C}$. Thirdly, the values of the fracture energy for the I-notched specimen being tested at ambient temperature also appeared different from expectations.

The mentioned "variations" are most probably related to the influence of the testing temperature as well as of the stressstrain state in the loaded specimens. From the microscale 
TABLE 3: Fracture energy of 17Mn1Si steel specimens with different notches under impact bending.

\begin{tabular}{|c|c|c|c|c|c|c|c|c|c|}
\hline \multirow{3}{*}{$T,{ }^{\circ} \mathrm{C}$} & \multicolumn{9}{|c|}{ Fracture energy, $A, \mathrm{~J}$} \\
\hline & \multicolumn{3}{|c|}{ V-notch } & \multicolumn{3}{|c|}{ U-notch } & \multicolumn{3}{|c|}{ I-notch } \\
\hline & $A_{t}$ & $A_{i}$ & $A_{p}$ & $A_{t}$ & $A_{i}$ & $A_{p}$ & $A_{t}$ & $A_{i}$ & $A_{p}$ \\
\hline-60 & 7.26 & 2.47 & 4.79 & 25.02 & 20.22 & 4.80 & 7.35 & 2.06 & 5,29 \\
\hline-40 & 15.82 & 4.86 & 10.96 & 35.53 & 7.91 & 27.62 & 14.47 & 3.36 & 11,11 \\
\hline-20 & 36.27 & 18.31 & 17.96 & 51.55 & 38.76 & 12.79 & 37.98 & 7.65 & 30,33 \\
\hline 0 & 47.11 & 7.25 & 39.86 & 68.39 & 41.59 & 26.80 & 48.01 & 7.39 & 40,62 \\
\hline 20 & 57.51 & 27.37 & 30.14 & 80.75 & 37.55 & 43.20 & 55.15 & 21.13 & 34,02 \\
\hline
\end{tabular}

$i$ initiation; $p$ : propagation.

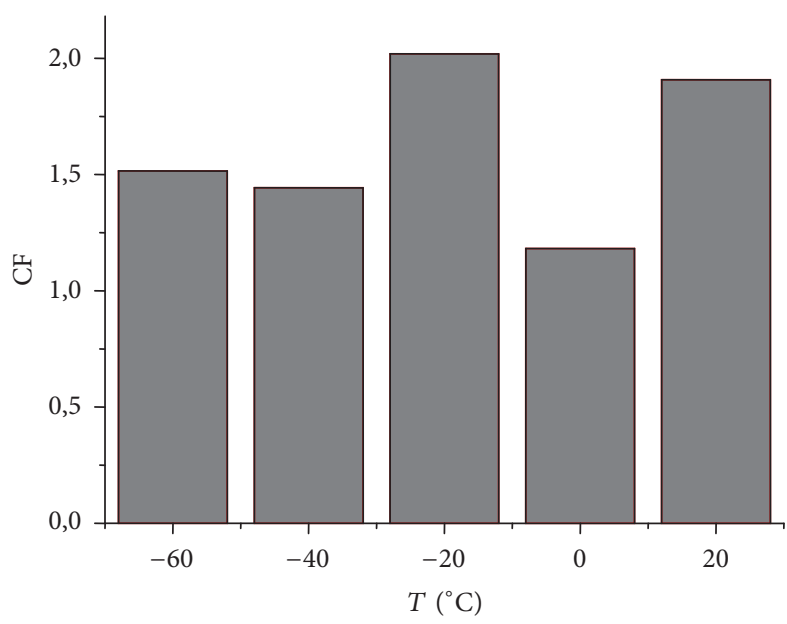

(a)

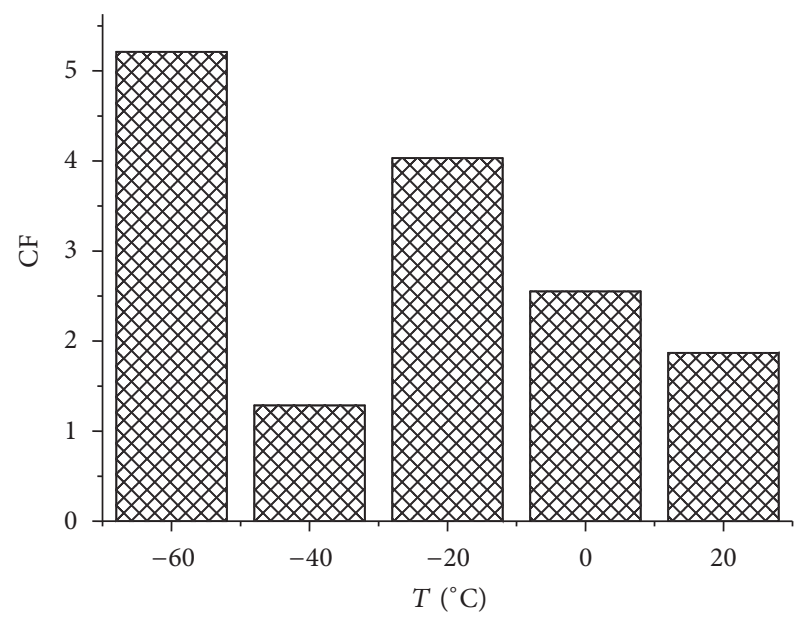

(b)

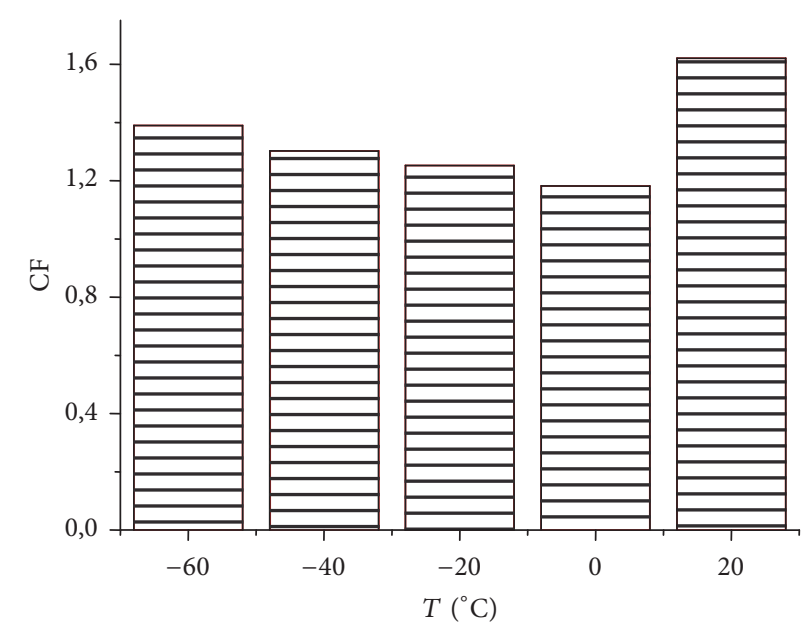

(c)

Figure 2: Temperature dependence of the CF parameter for 17Mn1Si steel specimens with V-notch (a), U-notch (b), and I-notch (c).

fracture mechanism point of view, it should be underlined that irreversible deformations under quasi-brittle fracture are rather low while fracture energy is predominantly determined by the stress stiffness parameters. Under ductile failure, the decisive role is related to accumulated plastic strains $[18,19]$. The experimental data presented in Tables 3 and 4 highlight the fact that the fracture energy in the brittle-toductile transition regime is fundamentally influenced by the stress stiffness. Furthermore, this assumption is supported by the data on the width of the ductile deformation zone where the coalescence of the microcracks gives rise to the main crack.

As has been said above, there is a correlation between the amount of plastic strains and external view of pipe fracture surfaces in full-scale air pressurization tests. Similar correlations were observed in the laboratory conditions on 


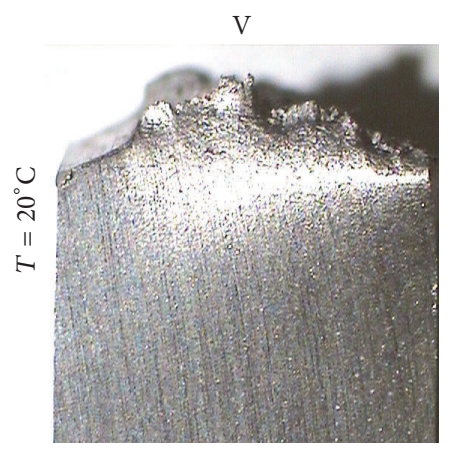

(a)

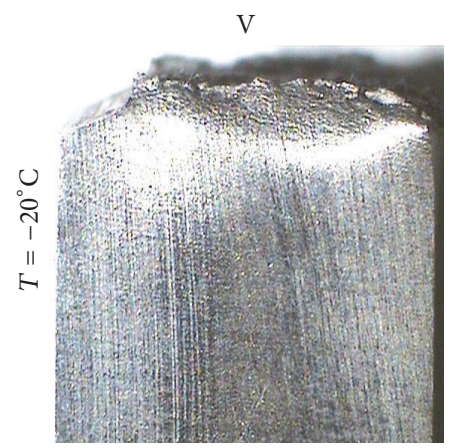

(d)

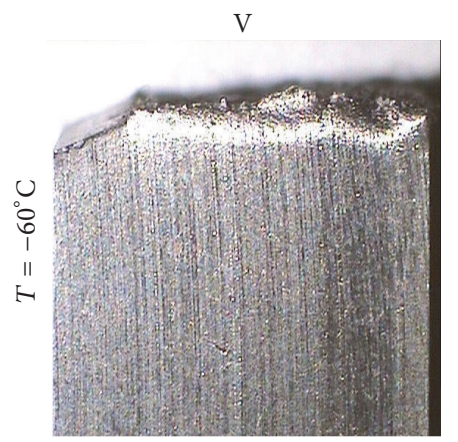

(g)

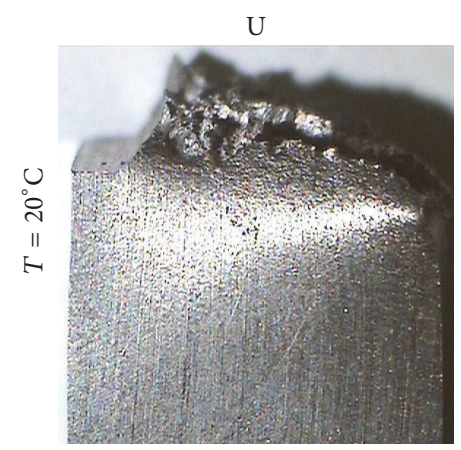

(b)

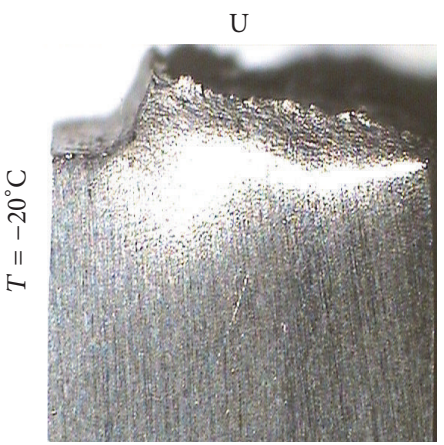

(e)

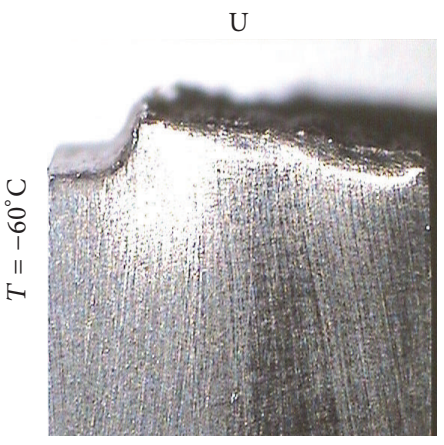

(h)

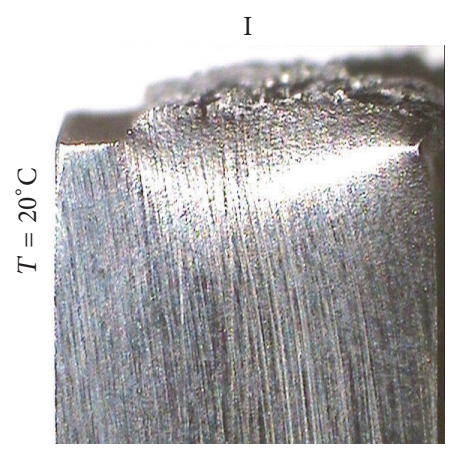

(c)

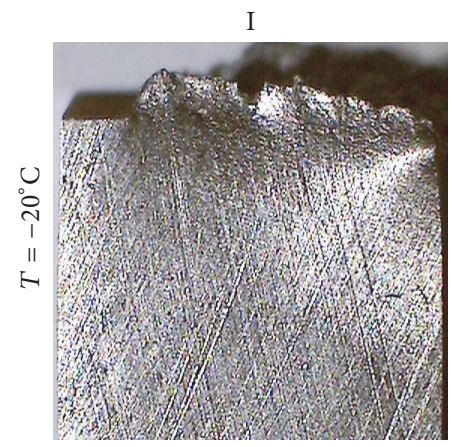

(f)

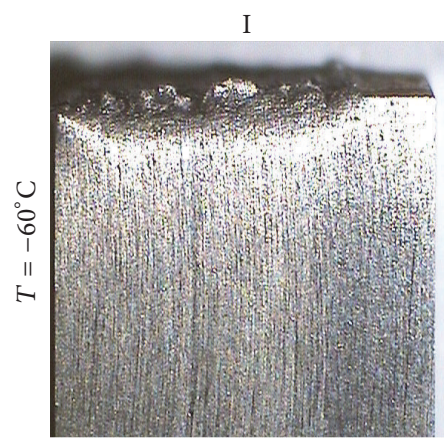

(i)

FIGURE 3: Optical images of the shear lips in specimens with V-notch (a), U-notch (b), and I-notch (c) for the test temperature $T=20^{\circ} \mathrm{C}$.

TABLE 4: Impact toughness test results for 17Mn1Si steel.

\begin{tabular}{lccc}
\hline \multirow{2}{*}{${ }^{\circ} \mathrm{C}$} & \multicolumn{3}{c}{ Impact toughness, $/ \mathrm{cm}^{2}$} \\
\hline-60 & V-notch & U-notch & I-notch \\
-40 & $9.3 \pm 1.1$ & $32 \pm 2.8$ & $9.4 \pm 1.3$ \\
-20 & $20 \pm 2.3$ & $46 \pm 2.5$ & $18 \pm 2.7$ \\
0 & $46 \pm 3.4$ & $51.6 \pm 2.2$ & $38 \pm 2.6$ \\
20 & $60 \pm 2.6$ & $87 \pm 3.9$ & $61 \pm 3.7$ \\
\hline
\end{tabular}

Charpy specimens [3]. In this paper, we use shear lips as the dynamic crack resistance parameters. The effect of macroscopic impact loading on specimens with differently shaped notches is revealed by the shape and height of the shear lips characterizing the elastic-plastic deformation during mutual rotational displacement of the specimen halves and reflecting the microscopic mechanisms related to the presence (or absence) of microasperities on the fracture surfaces on the microscale.

4.1.1. Shear Lips as an Indicator of the Deformation Process. The impact loading develops a strain field ahead of the notch tip $[20,21]$. The shape and size of this field depend on the concentrator type. Additionally, this zone acts as an elasticplastic "hinge" about which specimen parts mutually rotate [22]. In this case, the height of the shear lips corresponds to the upper boundary of the generated strain field while their appearance characterizes the "response" to fracture (Figure 3).

$V$-Notch. Shear lips at $T=20^{\circ} \mathrm{C}$ have rounded shape, showing that the material has significant ductility (Figure 3(a)). At the same time, there are ruptures on the surface, pointing to 
inhomogeneous strain localization in the stress concentrator zone and at crack propagation $[23,24]$. At $T=-20^{\circ} \mathrm{C}$, plastic strain localization and partial stress relaxation occur which lead to a decrease in the volume of plastically deformed metal. Thus, shear lips become less rounded (Figure 3(d)). At $T=$ $-60^{\circ} \mathrm{C}$, one can see a further decrease in material's plasticity and fracture localization. Shear lips take a "degenerated" shape typical of low-temperature tests (Figure 3(g)).

$U$-Notch. At $T=20^{\circ} \mathrm{C}$, shear lips are elongated with locally torn out material along the front (Figure 3(b)). This is a clear demonstration of necking in the specimen cross section at crack initiation, which is an example of inhomogeneous plastic deformation. The maximum plastic strain degree is observed on the stage of fracture initiation, particularly in the crack initiation region where a large surface area is involved in plastic deformation. The test temperature reduction down to $T=-20^{\circ} \mathrm{C}$ and then to $T=-60^{\circ} \mathrm{C}$ exerts almost no effect on the shape of shear lips in the U-notched specimens (Figures $3(\mathrm{e})$ and $3(\mathrm{~h}))$.

I-Notch. Shear lips at the temperatures $T=20^{\circ} \mathrm{C}$ and $T=-20^{\circ} \mathrm{C}$ appear in the form typical of ductile fracture, resembling the shear lips in the $\mathrm{V}$-notched specimens (Figures 3(c) and 3(d)). This can be indicative of high-energy crack propagation characterized by high plastic strains. At the same time, at $T=-60^{\circ} \mathrm{C}$, the profile of shear lips takes on the form typical of cleavage fracture, and the lips become "degenerated" (Figure 3(i)).

4.1.2. Macroscopic Analysis of Fracture Surface Morphology. Analysis of laboratory and full-scale air pressurization test data has shown that the capability to arrest ductile fracture is determined by the volume and intensity of plastic deformation ahead of the propagating crack tip [3]. In so doing, the volume of plastically deformed metal ahead of the crack tip remains almost unchanged on the stage of stable ductile crack growth [3]. The larger the volume of plastic deformation near the propagating crack and the greater the plastic strains, the shorter the fracture time. The crack growth energy and the presence of plastic strains contractions along the crack front in Charpy specimens are main factors attesting to high mechanical properties of pipe steel [25-28].

$T=20^{\circ} \mathrm{C}$ (for $V-, U_{-}$, and I-Notches). The crack initiation zone (zone I) is characterized by transition from the notch at an oblique angle, which points to the presence of macroand microplastic strains. This is also confirmed by the shape of shear lips (Figures 4(a)-4(c)). The fracture surface appearance (zone II) is typical of shear rupture. This bears witness to the formation of a plastic zone ahead of the notch tip and to a heterogeneous stress-strain state in the specimen at crack initiation and growth. In this case, fracture is determined by the inhomogeneity of energy absorption in different specimen regions, particularly in the zone of shear lips (zone III), which results in different appearance of the final specimen rupture (zone IV).
$T=-20^{\circ} \mathrm{C}$ (for $V-, U-$, and I-Notches). The influence of plastic deformation decreases with decreasing temperature. This affects the appearance of the specimen fracture surfaces (Figures 4(d)-4(f)). The crack initiation and crack propagation zones (zones I and II) are formed in a ductile manner with local regions of plastic flow. The multifaceted fracture surface is typical of cleavage in a polycrystalline material. Local strain localization occurs through multiple necking, and thus the volume of plastically deformed metal decreases, including the zones of shear lips (zone III) and final specimen rupture (zone IV).

$T=-60^{\circ} \mathrm{C}$ (for $V$-, $U$-, and I-Notches). The regions of crack initiation (zone I) and growth (zone II and zone IV) exhibit flat surfaces without visible signs of material tear at the macroscale. This means that crack propagation along the entire front occurred in stationary conditions, that is, in nearly the same stress-strain state along the entire front (Figures $4(\mathrm{~g})-4(\mathrm{i}))$. In this case, crack initiation corresponded to the transition of material to the nonequilibrium state. Fracture in this zone is brittle. The strain rates, shear strain, and tangential stress values exerted almost no effect on microscopic fracture mechanisms. Notice that the fracture surface of all specimens is flat on the macroscale with a small zone of shear lips (zone III) regardless of the notch shape. The performed tests have shown that with the increasing stress stiffness induced by temperature reduction and strain localization $[29,30]$ the material transits to a more brittle state and hence its fracture energy decreases [31].

\subsubsection{Microscopic Fracture Mechanisms}

\section{(1) Crack Initiation Zone (Zone I)}

$T=20^{\circ} \mathrm{C}$. The surface of the crack initiation zone shows characteristic signatures of ductile fracture (Figures 5(a)$5(c))$ where large dimples are surrounded by conglomerates of smaller dimples. Although the dimple shapes and sizes differ, the physical nature of their formation is similar for all specimens regardless of the shape of notches.

$T=-20^{\circ} \mathrm{C}$. Fracture mechanisms are different for different specimens:

(i) The fracture of V-notched specimens is similar to that observed at $T=20^{\circ} \mathrm{C}$. Ductile fracture dimples are however smaller in size (Figure 5(d)).

(ii) The fracture surface in U-notched specimens is formed with the appearance of delamination regions [31-33] that are nucleated at large nonmetallic inclusions.

(iii) The fracture surface in I-notched specimens has brittle (quasi-brittle) “faceted" fracture relief (Figure 5(f)) and individual zones with ductile microrelief.

$T=-60^{\circ} \mathrm{C}$. The major fracture mechanism at this temperature is cleavage featured by the following observations for different specimens: 
$\mathrm{V}$

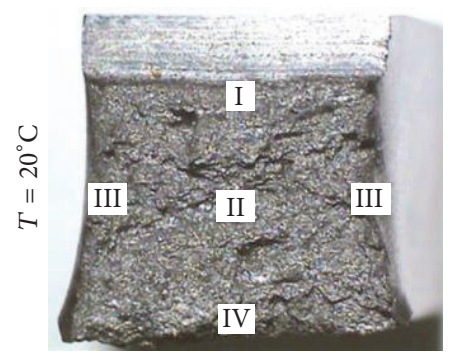

(a)

$\mathrm{V}$

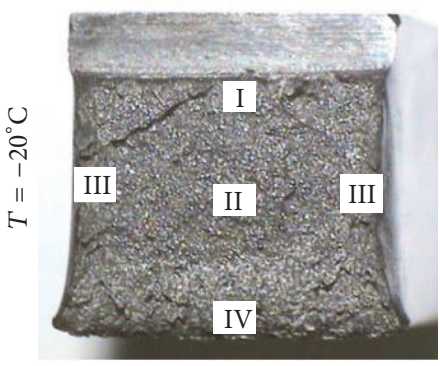

(d)

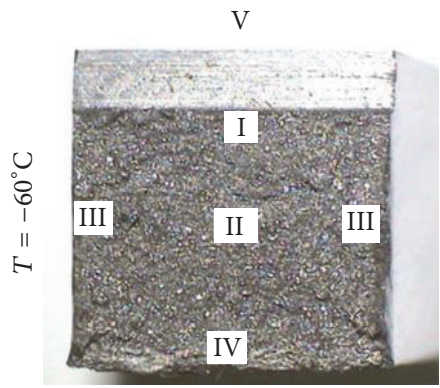

(g)
$\mathrm{U}$

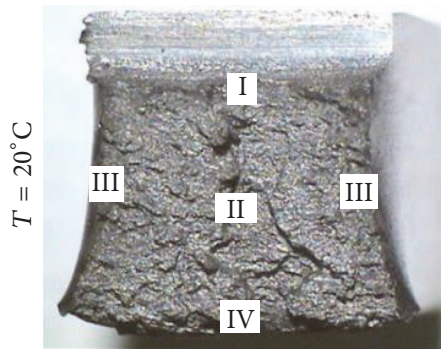

(b)

$\mathrm{U}$

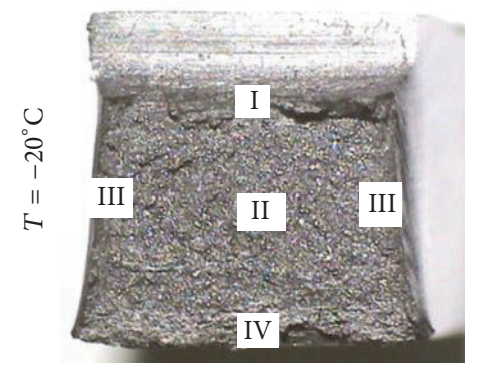

(e)

$\mathrm{U}$

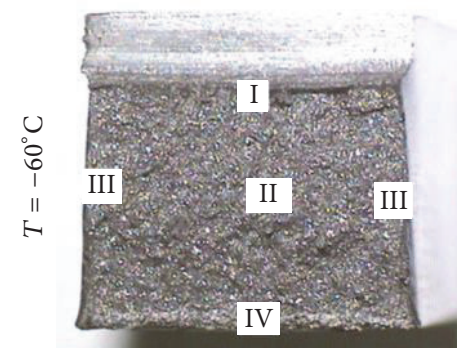

(h)

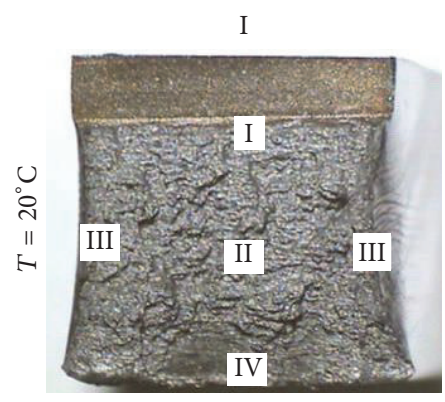

(c)

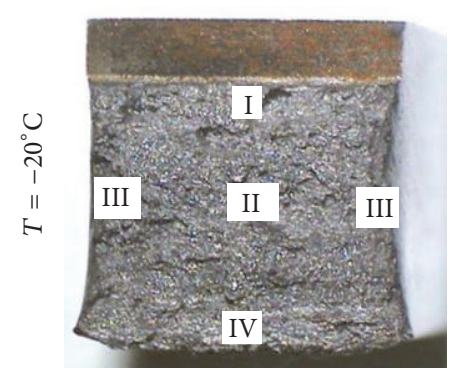

(f)

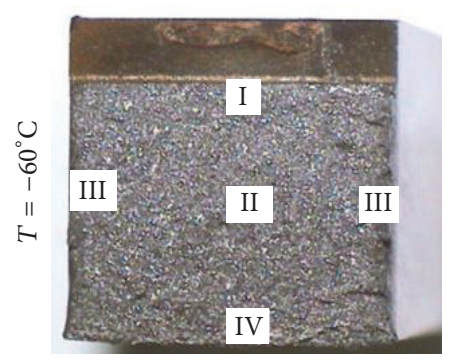

(i)

FIgURE 4: Macroscopic aspects of fracture surface of specimens impact tested at different temperatures. Fracture zones are labelled as (I) crack initiation, (II) crack growth, (III) shear lips, and (IV) final rupture.

(i) The fracture surface in V-notched specimens exhibits a river-like pattern (Figure $5(\mathrm{~g})$ ). It is covered by cleavage ridges formed by the coalescence of microcracks on parallel surface areas under the action of accompanying plastic deformation.

(ii) The fracture mechanism for U-notched specimens is complex (Figure 5(i)). Although the major mechanism is undoubtedly cleavage, the microdimples can be also clearly discerned on the surface. The combination of these fracture mechanisms makes the surface highly disordered.

(iii) The fracture mechanism for I-notched specimens can be associated with quasi-cleavage (Figure 5(h)) which is a mixed mechanism involving both microvoid coalescence and cleavage: zones of brittle fracture facets are surrounded by regions of microdimpled ductile fracture.

Fracture micromechanisms for impact bending test specimens are classified in Table 5.

\section{(2) Crack Propagation Zone}

$T=20^{\circ} \mathrm{C}$. Fracture surface exhibits all characteristic signatures of ductile fracture (Table 6):

(i) The fracture surface in V-notched specimens consists of ductile dimples (Figure 6(a)) that are conventionally associated with the coalescence of microvoids. The nucleation centers of ductile fracture dimples are commonly related to second-phase particles, grain boundaries, and interphase (particle/matrix interfaces) boundaries.

(ii) The crack propagation zone in U-notched specimens also has dimples of ductile origin: shear dimples (Figure 6(b)). Their profile is "smeared" along one of the axes, which points to significant plastic deformation and a strong influence of shear strains.

(iii) The fracture surface in I-notched specimens is formed by the ductile mechanism, but the observed dimples are shallow, the so-called "flat-bottomed" dimples 


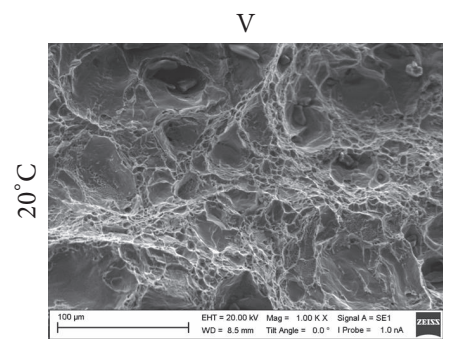

(a)

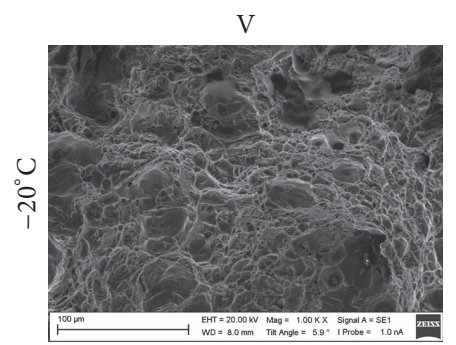

(d)

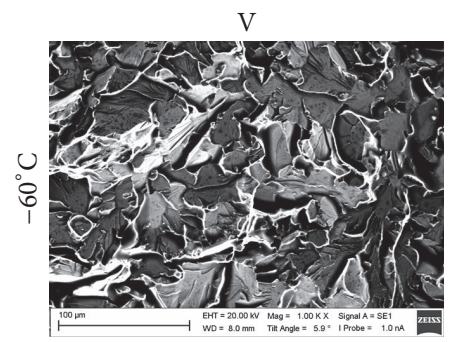

(g)

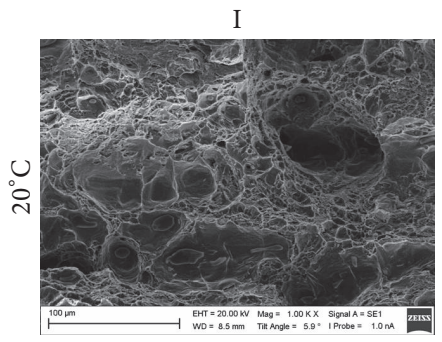

(b)

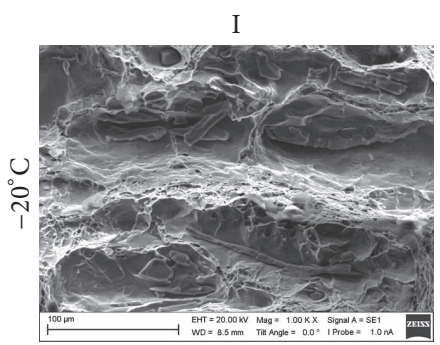

(e)

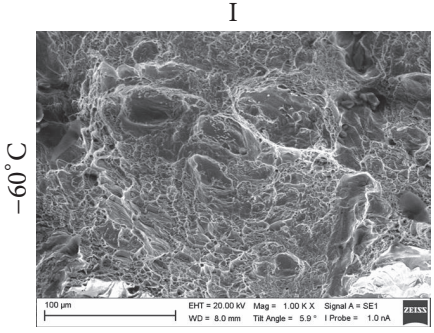

(h)

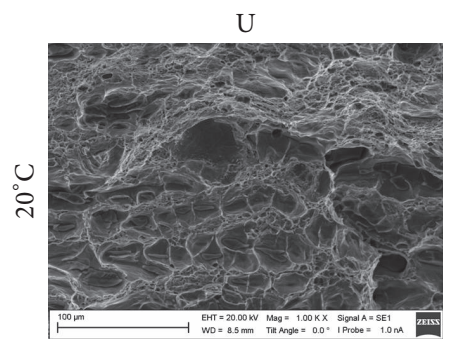

(c)

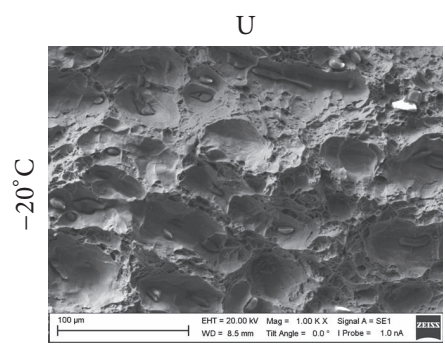

(f)

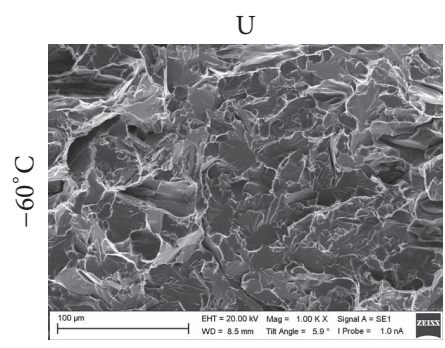

(i)

FIGURE 5: SEM fracture surfaces of crack initiation zone in specimens with different-shaped notches after impact bending test at different temperatures.

TABLE 5: Fracture micromechanisms in the crack initiation zone for specimens with different-shaped concentrators.

\begin{tabular}{lccc}
\hline $\begin{array}{l}\text { Test } \\
\text { temperature }\end{array}$ & $\mathrm{V}$ & Notch shape & $\mathrm{U}$ \\
\hline$T=20^{\circ} \mathrm{C}$ & $\begin{array}{c}\text { Ductile fracture with macrodimples of } \\
\text { size } 40-80 \mu \mathrm{m}\end{array}$ & $\begin{array}{c}\text { Ductile fracture with macro- and } \\
\text { microdimples }\end{array}$ & $\begin{array}{c}\text { Ductile fracture with macrodimples of } \\
\text { size } \sim 40 \mu \mathrm{m}\end{array}$ \\
$T=-20^{\circ} \mathrm{C}$ & $\begin{array}{c}\text { Ductile fracture with macro- and } \\
\text { microdimples }\end{array}$ & Ductile-brittle delaminations & Facet fracture, ductile-brittle fracture \\
$T=-60^{\circ} \mathrm{C}$ & $\begin{array}{c}\text { Brittle fracture with river-like fracture } \\
\text { pattern }\end{array}$ & $\begin{array}{c}\text { Ductile-brittle fracture with facets }+ \\
\text { microdimples }\end{array}$ & $\begin{array}{c}\text { Brittle fracture with partial local } \\
\text { microscopically ductile ridges }\end{array}$ \\
\hline
\end{tabular}

TABLE 6: Fracture micromechanisms in the crack propagation zone for specimens with different-shaped notches.

\begin{tabular}{|c|c|c|c|}
\hline \multirow{2}{*}{$\begin{array}{l}\text { Test } \\
\text { temperature }\end{array}$} & \multicolumn{3}{|c|}{ Notch shape } \\
\hline & $\mathrm{V}$ & $\mathrm{U}$ & I \\
\hline$T=20^{\circ} \mathrm{C}$ & & Dimpled ductile fracture & \\
\hline$T=-20^{\circ} \mathrm{C}$ & Brittle (flat cleavage facets) & Brittle (cleavage facets) & $\begin{array}{l}\text { Brittle (cleavage facets }+ \text { local } \\
\text { microdimples) }\end{array}$ \\
\hline$T=-60^{\circ} \mathrm{C}$ & Brittle fracture with cleavage facets & $\begin{array}{l}\text { Brittle fracture with cleavage facets } \\
\text { and local microcracks }\end{array}$ & Brittle fracture with cleavage facets \\
\hline
\end{tabular}




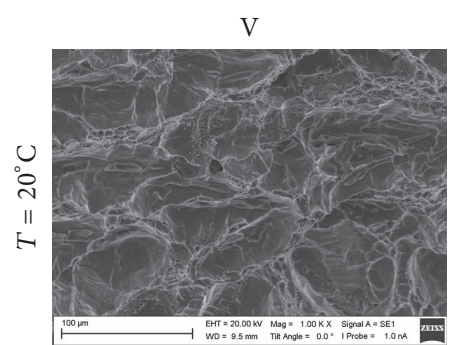

(a)

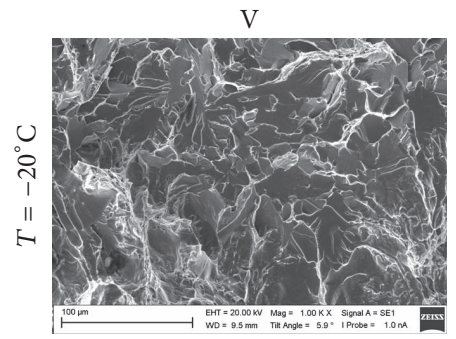

(d)

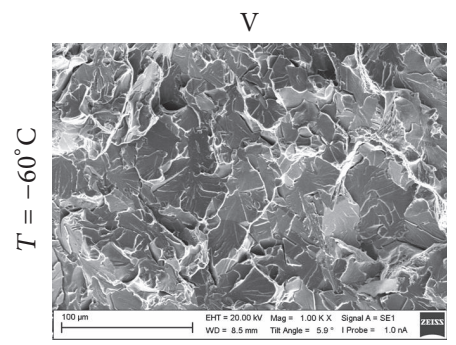

(g)

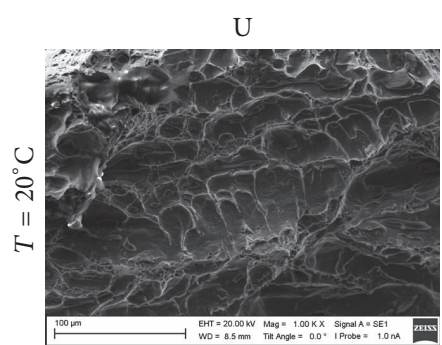

(b)

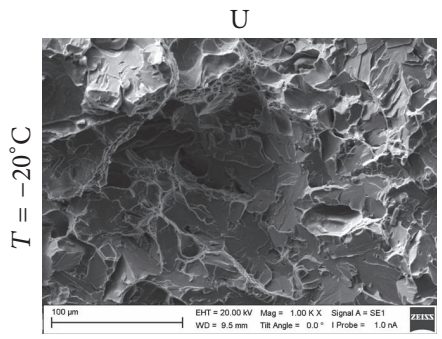

(e)

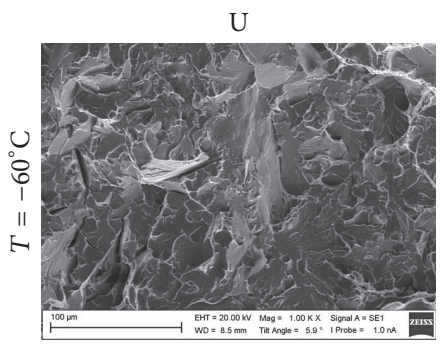

(h)

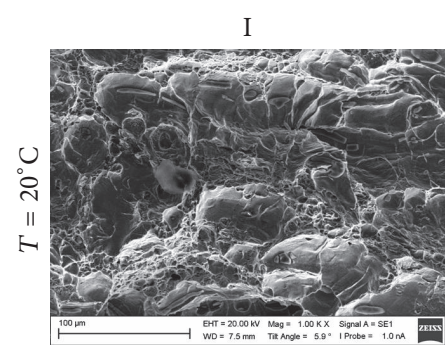

(c)

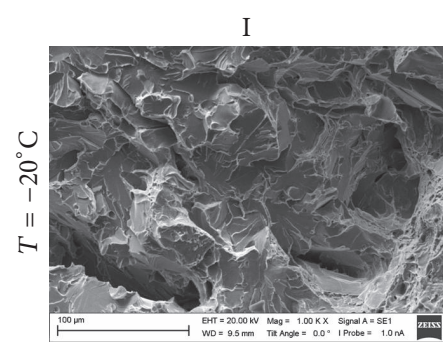

(f)

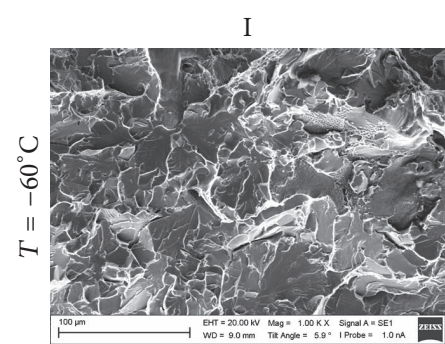

(i)

FIGURE 6: Fracture surfaces corresponding to the crack propagation zone in the specimens tested in impact bending at different temperatures.

(Figure 6(c)). Generally, the underlying mechanism can be loosely interpreted as ductile, but its nature is somewhat different from that defined for specimens with less sharp $\mathrm{V}$ - and U-notches.

Thus, we have shown that the notch shape strongly affects the morphology of the formed ductile fracture dimples.

$T=-20^{\circ} \mathrm{C}$. We revealed no significant qualitative difference in the microstructure of fracture surfaces in the studied specimens at this temperature. Nevertheless, some interesting features are worth noting:

(i) The fracture surface in V-notched specimens is characterized by the presence of brittle structural elements, such as cleavage facets, terraces, and individual regions with quasi-ductile microrelief, and by zones of local microdeformation (Figure 6(d)).

(ii) The quasi-cleavage fracture mechanism in U- and Inotched specimens also includes the nucleation of transgranular cleavage microcracks in the bulk of structural elements and subsequent coalescence of neighboring brittle microcracks with rupture of ductile (plastic) metal ligaments between them. Part of these cracks do not have enough energy for propagation and remained as voids or delaminations (Figures $6(d)-6(f))$.

$T=-60^{\circ} \mathrm{C}$

(i) The fracture surface in V-and I-notched specimens is formed by crystalline brittle fracture along cleavage planes with facet formation on the surface (Figures 6(g) and 6(h)). Most probably, the brittle crack initiation is due to splitting of one or several grains near the stress concentrator. The low-energy crack propagation is confirmed by the absence of the zone of stable defect propagation and contractions and by brittle fracture prevalence [32].

(ii) The U-notched specimens exhibit relatively "flat" brittle fracture facets. Periphery regions of quasicleavage facets have well-defined contours that bear witness to the absence of microplastic strains in these metal volumes (Figure 6(i)).

\section{Conclusion}

An approach towards fracture characterization has been suggested based on the description of elastic-plastic deformation 
of impact loaded specimens on the stage of crack initiation and growth at ambient and lower temperatures. The analysis of the shape of impact loading diagrams and energy fracture values for impact loaded specimens of pipe $17 \mathrm{Mn} 1 \mathrm{Si}$ steel revealed the fracture mechanisms of this steel depending on the notch shape.

It was found that the test temperature reduction plays the decisive role in plastic strain localization and subsequent impact fracture of specimens with different-shaped notches. This is reflected in localization of deformation processes, decrease in crack propagation energy, and "degradation" of shear lips.

The present work represents a logical extension of the approach that utilizes the shape of shear lips as an informative feature (both qualitative and quantitative) in fracture diagnostics. A classification of fracture macro- and microscopic mechanisms for differently notched specimens tested at different temperatures was proposed, which enabled selfconsistent interpretation of impact test results.

\section{Competing Interests}

The authors declare that they have no competing interests.

\section{Acknowledgments}

This work was performed in the framework of fundamental research projects of the Russian State Academies of Sciences (2013-2020), with a partial support of RFBR Grant no. 1508-05818_a, and Project of the Headquarter of the Russian Academy of Sciences on Artic Research. The authors are grateful to the Shared Use Center "Nanotech" of ISPMS SB RAS for the assistance in fractographic investigations.

\section{References}

[1] S. H. Hashemi, "Apportion of Charpy energy in API 5L grade X70 pipeline steel," International Journal of Pressure Vessels and Piping, vol. 85, no. 12, pp. 879-884, 2008.

[2] A. B. Arabei, I. Y. Pyshmintsev, V. M. Farber, V. A. Khotinov, and A. O. Struin, "Failure of pipe steel of X80 (K65) strength class," Steel in Translation, vol. 42, no. 3, pp. 212-218, 2012.

[3] P. E. O’Donoghue, M. F. Kanninen, C. P. Leung, G. Demofonti, and S. Venzi, "The development and validation of a dynamic fracture propagation model for gas transmission pipelines," International Journal of Pressure Vessels and Piping, vol. 70, no. 1, pp. 11-25, 1997.

[4] M. Ben Amara, G. Pluvinage, J. Capelle, and Z. Azari, "Crack tip opening angle as a fracture resistance parameter to describe ductile crack extension and arrest in steel pipes under service pressure," Physical Mesomechanics, vol. 18, no. 4, pp. 355-369, 2015.

[5] C.-K. Oh, Y.-J. Kim, J.-H. Baek, Y.-P. Kim, and W. Kim, "A phenomenological model of ductile fracture for API X65 steel," International Journal of Mechanical Sciences, vol. 49, no. 12, pp. 1399-1412, 2007.

[6] I. Y. Pyshmintsev, A. B. Arabei, V. M. Farber, V. A. Khotinov, and N. V. Lezhnin, "Laboratory criteria of crack resistance of highstrength steels for gas main pipelines," The Physics of Metals and Metallography, vol. 113, no. 4, pp. 411-417, 2012.
[7] P. Maruschak, R. Bishchak, O. Prentkovskis, L. Poberezhnyi, I. Danyliuk, and G. Garbinčius, "Peculiarities of the static and dynamic failure mechanism of long-term exploited gas pipeline steel," Advances in Mechanical Engineering, vol. 8, no. 4, pp. 1-8, 2016.

[8] R. W. Hertzberg, Deformation and Fracture Mechanics of Engineering Materials, John Wiley \& Sons, Chichester, UK, 4th edition, 1996.

[9] ASTM E23, "Standard test methods for notched bar impact testing of metallic materials," in Annual Book of ASTM Standards, vol. 03.01, ASTM, West Conshohocken, Pa, USA, 2016.

[10] ISO, "Metallic materials—charpy pendulum impact test-part 1: test method," ISO 148-1:2009, International Organization for Standardization (ISO), Vernier, Geneva, Switzerland, 2009.

[11] S. H. Hashemi, "Correction factors for safe performance of API X65 pipeline steel," International Journal of Pressure Vessels and Piping, vol. 86, no. 8, pp. 533-540, 2009.

[12] S. A. Kotrechko and Y. Y. Meshkov, "Physical interpretation of fracture characteristics determined in testing Charpy specimens by impact bending," Strength of Materials, vol. 33, no. 4, pp. 356-361, 2001.

[13] S. H. Hashemi, D. Mohammadyani, M. Pouranvari, and S. M. Mousavizadeh, "On the relation of microstructure and impact toughness characteristics of DSAW steel of grade API X70," Fatigue \& Fracture of Engineering Materials \& Structures, vol. 32, no. 1, pp. 33-40, 2009.

[14] P. K. C. Venkatsurya, R. D. K. Misra, M. D. Mulholland, M. Manohar, and J. E. Hartmann, "The impact of microstructure on yield strength anisotropy in linepipe steels," Metallurgical and Materials Transactions A, vol. 45, no. 5, pp. 2335-2342, 2014.

[15] P. O. Maruschak, I. M. Danyliuk, R. T. Bishchak, and T. Vuherer, "Low temperature impact toughness of the main gas pipeline steel after long-term degradation," Central European Journal of Engineering, vol. 4, no. 4, pp. 408-415, 2014.

[16] P. V. Yasniy, P. O. Maruschak, R. T. Bishchak, and S. V. Panin, "Degradation processes in heat resistant steel during long-term service," in Proceedings of the International Conference "InService Damage of Materials, Its Diagnostics and Prediction”, pp. 196-201, TSTU, Ternopil, Ukraine, September 2009.

[17] G. C. Sih and D. Y. Tzou, "Dynamic fracture rate of Charpy Vnotch specimen," Theoretical and Applied Fracture Mechanics, vol. 5, no. 3, pp. 189-203, 1986.

[18] P. O. Marushchak, R. T. Bishchak, B. Gliha, and A. P. Sorochak, "Influence of temperature on the impact toughness and dynamic crack resistance of $25 \mathrm{Kh} 1 \mathrm{M1F}$ steel," Materials Science, vol. 46, no. 4, pp. 568-572, 2011.

[19] P. V. Yasnii, Y. I. Pyndus, V. B. Glad'o, I. B. Okipnyi, and I. V. Shul'gan, "Scientific and technical section FEM prediction of the influence of warm prestressing on fracture toughness of heatresistant steel," Strength of Materials, vol. 43, no. 2, pp. 113-121, 2011.

[20] D. J. Ayres, "Dynamic plastic analysis of ductile fracture-the Charpy specimen," International Journal of Fracture, vol. 12, no. 4, pp. 567-578, 1976.

[21] T. R. Wilshaw and P. L. Pratt, "On the plastic deformation of charpy specimens prior to general yield," Journal of the Mechanics and Physics of Solids, vol. 14, no. 1, pp. 7-19, 1966.

[22] P. O. Maruschak, A. P. Sorochak, T. Vuherer, O. Prentkovskis, O. P. Yasniy, and R. T. Bishchak, "Impact toughness and deformation parameters of fracture of railway axle material," Arabian Journal for Science and Engineering, vol. 41, no. 5, pp. 1647-1655, 2016. 
[23] S. O. Kotrechko, A. Y. Krasowsky, Y. Y. Meshkov, and V. M. Torop, "Long-term service effect on the toughness of pipeline steel 17GS," International Journal of Fracture, vol. 128, no. 1, pp. 171-182, 2004.

[24] R. Cao, G. Li, X. Y. Fang, J. Song, and J. H. Chen, "Investigation on the effects of microstructure on the impact and fracture toughness of a C-Mn steel with various microstructures," Materials Science and Engineering A, vol. 564, pp. 509-524, 2013.

[25] S. Y. Shin, "Effects of microstructure on tensile, charpy impact, and crack tip opening displacement properties of two API X80 pipeline steels," Metallurgical and Materials Transactions A, vol. 44, no. 6, pp. 2613-2624, 2013.

[26] X.-L. Yang, Y.-B. Xu, X.-D. Tan, and D. Wu, "Influences of crystallography and delamination on anisotropy of Charpy impact toughness in API X100 pipeline steel," Materials Science and Engineering A, vol. 607, pp. 53-62, 2014.

[27] Y. J. Chao, J. D. Ward Jr., and R. G. Sands, "Charpy impact energy, fracture toughness and ductile-brittle transition temperature of dual-phase 590 Steel," Materials and Design, vol. 28, no. 2, pp. 551-557, 2007.

[28] M. W. Wu, L. C. Tsao, G. J. Shu, and B. H. Lin, “The effects of alloying elements and microstructure on the impact toughness of powder metal steels," Materials Science and Engineering A, vol. 538, pp. 135-144, 2012.

[29] M. P. Savruk and A. Kazberuk, "A unified approach to problems of stress concentration near V-shaped notches with sharp and rounded tip," International Applied Mechanics, vol. 43, no. 2, pp. 182-197, 2007.

[30] A. Kazberuk, M. P. Savruk, and A. B. Chornenkyi, "Stress distribution at sharp and rounded V-notches in quasi-orthotropic plane," International Journal of Solids and Structures, vol. 85-86, pp. 134-143, 2015.

[31] P. Lazzarin and F. Berto, "Some expressions for the strain energy in a finite volume surrounding the root of blunt V-notches," International Journal of Fracture, vol. 135, no. 1-4, pp. 161-185, 2005.

[32] B. Tanguy, J. Besson, R. Piques, and A. Pineau, "Ductile to brittle transition of an A508 steel characterized by Charpy impact test Part I: experimental results," Engineering Fracture Mechanics, vol. 72, no. 1, pp. 49-72, 2005.

[33] B. Tanguy, J. Besson, R. Piques, and A. Pineau, "Ductile to brittle transition of an A508 steel characterized by Charpy impact test: part II: modeling of the Charpy transition curve," Engineering Fracture Mechanics, vol. 72, no. 3, pp. 413-434, 2005. 

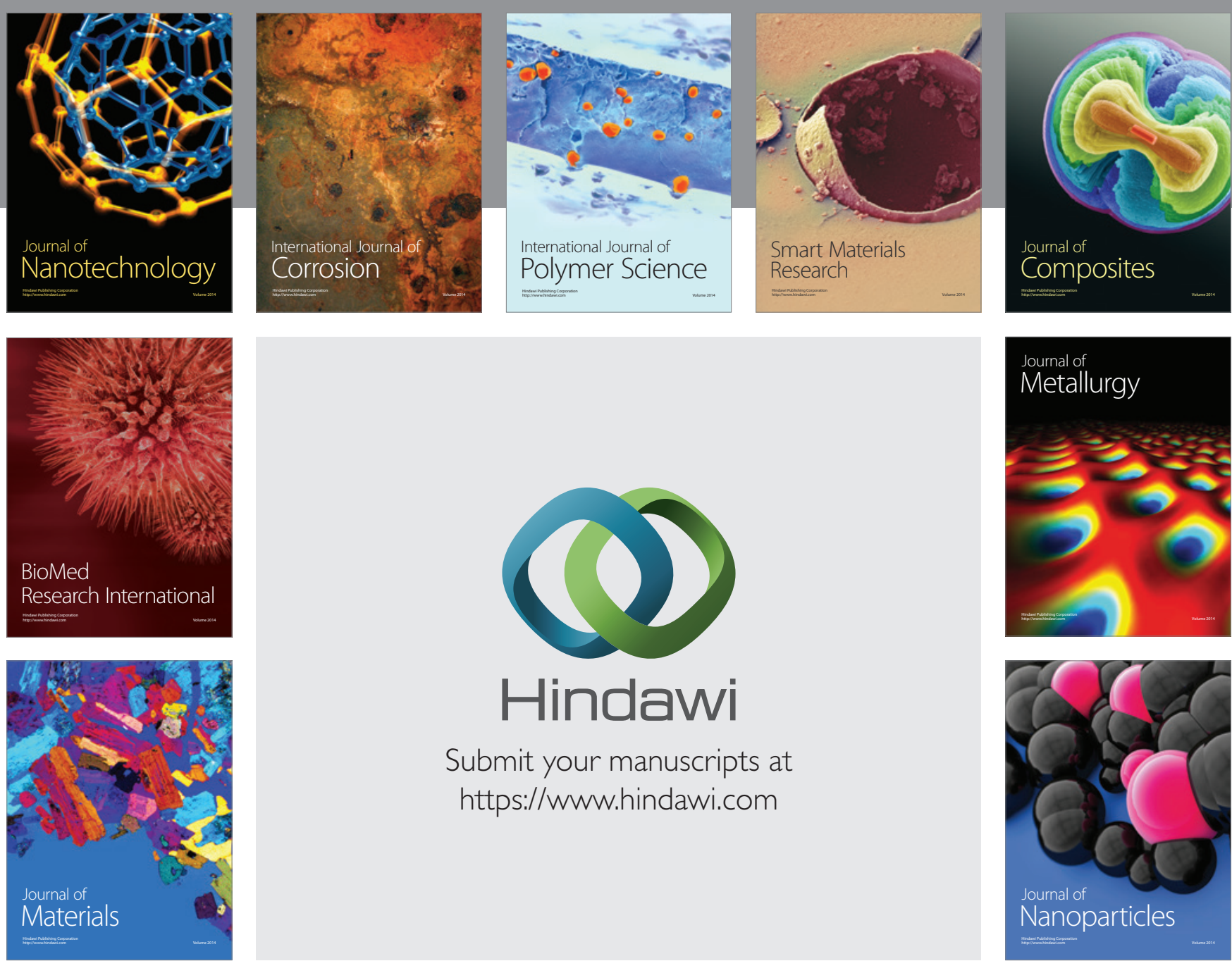

\section{Hindawi}

Submit your manuscripts at

https://www.hindawi.com

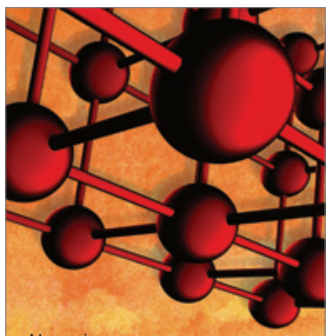

Materials Science and Engineering
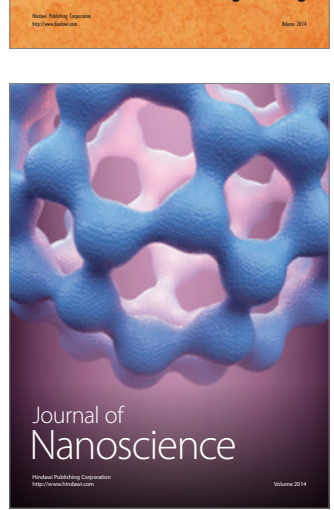
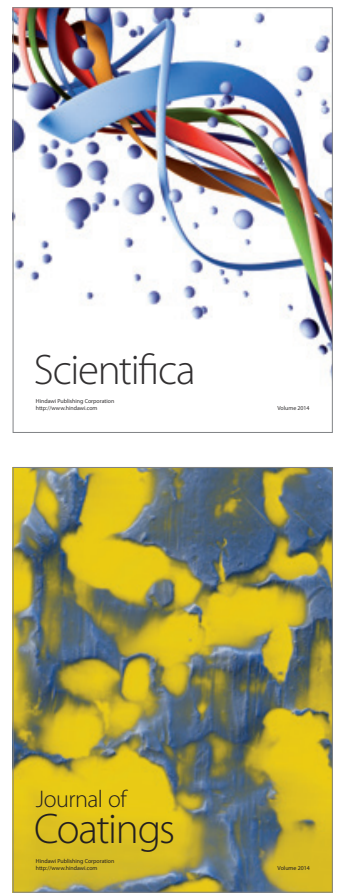
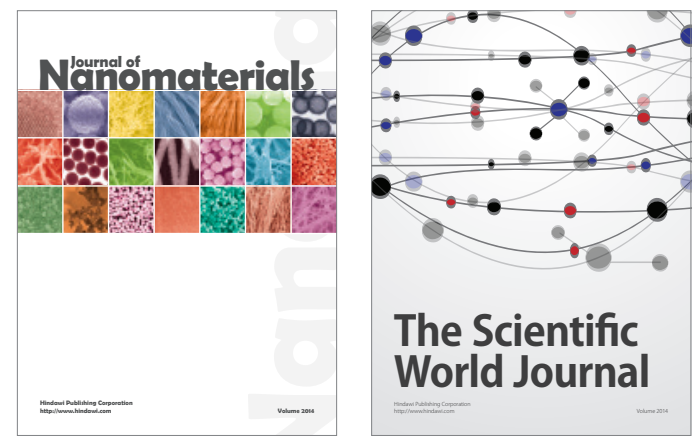

The Scientific World Journal
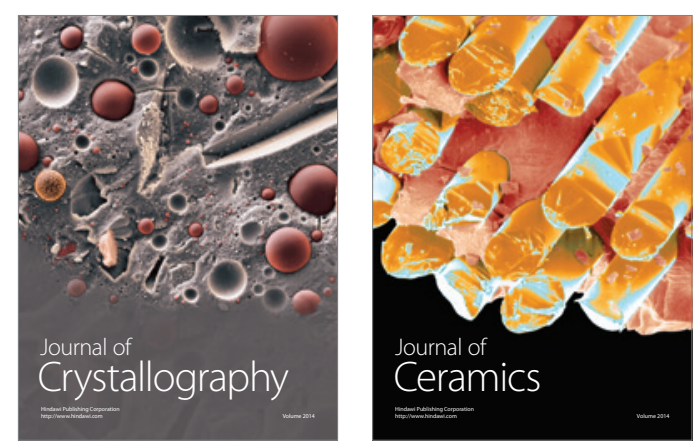
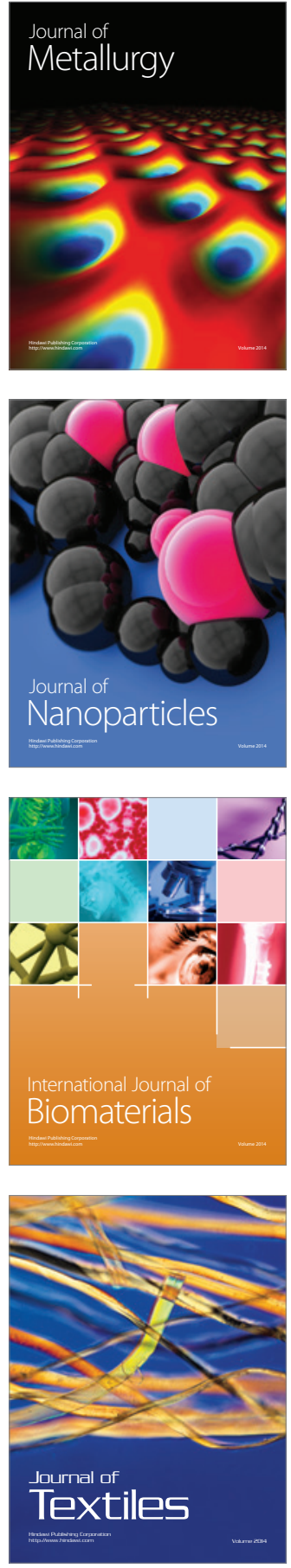